\title{
Caracterização do Regime Pluviométrico do Município de Araguaína - TO
}

\author{
Alesi Teixeira Mendes ${ }^{1,2}$ (D) , Joel Carlos Zukowski Junior ${ }^{1}$ \\ ${ }^{1}$ Programa de Pós-Graduação em Engenharia Ambiental, \\ Fundação Universidade Federal do Tocantins, Palmas, TO, Brasil. \\ ${ }^{2}$ Instituto Tocantinense Presidente Antônio Carlos, Porto Nacional, TO, Brasil.
}

Recebido em: 1 de Outubro de 2014 - Aceito em: 7 de Julho de 2015

\begin{abstract}
Resumo
O comportamento da chuva afeta o planejamento e operação dos setores da sociedade. Uma das formas de conhecer o comportamento das chuvas de uma determinada região é por meio da análise das séries históricas de precipitação. $\mathrm{O}$ objetivo desse trabalho é analisar e caracterizar o regime pluviométrico do município de Araguaína, com base nas séries históricas de estações pluviométricas da Agência Nacional de Águas (ANA). Além disso, são apresentadas informações regionalizadas que podem auxiliar o sistema de gestão do município de Araguaína para os setores que dependem da dinâmica das chuvas em suas tomadas de decisão. Foram selecionadas 5 estações com contribuição de registros de chuva direta no município. De forma geral, constatou-se que o ano hidrológico de Araguaína apresenta sazonalidade bem definida caracterizada por dois períodos: o período seco de maio a setembro, e o chuvoso de outubro a abril. A média de precipitação total anual em toda a área do município é de $1746,97 \mathrm{~mm}$ e, em média, $89 \%$ da precipitação total anual de Araguaína é registrada no período considerado chuvoso. Por outro lado, pouco mais de $10 \%$ do volume precipitado acontece fora dos meses de outubro a abril.
\end{abstract}

Palavras-chave: precipitação, preenchimento de falhas, regime pluviométrico.

\section{Characterization of the Pluviometric Regime of the Municipality of Araguaína - TO}

\begin{abstract}
The behavior of rain affects the planning and operation of society's sectors. One of the ways to know the behavior of the rains of a certain region is through the analysis of the historical series of precipitation. The objective of this work is to analyze and characterize the pluviometric regime of the municipality of Araguaína, based on the historical series of rainfall stations of the National Water Agency. In addition, regional information is presented that can help the management system of the municipality of Araguaína for the sectors that depend on the dynamics of the rainfall in its decisions. Five rain gauges were selected with contributions from direct rain records in the municipality. In general, it was verified that the hydrological year of Araguaína presents well defined seasonality characterized by two periods: the dry period from May to September, and the rainy season from October to April. The average annual precipitation in the entire area of the municipality is $1746.97 \mathrm{~mm}$ and, on average, $89 \%$ of Araguaina's total annual rainfall is recorded on the period considered rainy. On the other hand, a little more than $10 \%$ of the volume precipitations happens outside the months of October to April.
\end{abstract}

Keywords: precipitation, fault filling, pluviometric regime.

\section{Introdução}

Em razão das características tropicais do Brasil a absoluta maioria da precipitação do país cai sob a forma de chuva, cujos percentuais chegam a mais de $99 \%$
(Ayoade, 1986). Desse modo, convencionalmente, a medição dos volumes precipitados é pontual, realizada por meio de equipamentos denominados pluviômetros.

Autor de correspondência: Alesi Teixeira Mendes, alesi_atm@mail.uft.edu.br. 
A precipitação é tida por vários autores do meio científico como a variável climatológica mais importante na região tropical e, por conta da grande variabilidade espaço-temporal desse fenômeno, a compreensão da sua dinâmica é fundamental para a tomada de decisões (Santos et al., 2001; Moraes et al., 2005).

Com efeito, diversos setores da sociedade são diretamente afetados pelas chuvas: a agricultura, a pesca, a navegação, o abastecimento de água, o manejo das águas pluviais, entre outros. Dessa forma, são imprescindíveis a identificação e o conhecimento dos padrões de ocorrência das chuvas para o planejamento e operação desses setores (Soares et al., 2016).

Por outro lado, a intensificação das atividades humanas no ambiente tem provocado o aumento das temperaturas do planeta. Uma das consequências diretas da elevação da temperatura é a modificação do ciclo anual das chuvas, o que pode influenciar o aumento da frequência e da magnitude de eventos meteorológicos e hidrológicos extremos (Piazza et al., 2016; Tao et al., 2011).

Os eventos extremos de precipitação geram uma série de impactos negativos nas cidades, uma vez que possibilitam a ocorrência de enchentes, inundações e deslizamentos. Por sua vez, esses impactos negativos, principalmente nas áreas urbanas, interferem diretamente no funcionamento de setores sociais, econômicos e ambientais (Wanderley et al., 2014).

O Tocantins possui uma economia fortemente impactada pela atividade agrícola, logo, a análise e caracterização do regime das precipitações é de fundamental importância, por exemplo, para a tomada de decisão junto às práticas agrícolas em diversas regiões do estado (Oliveira Filho et al., 2001).

Quanto ao tema, Moraes et al. (2005) aponta que na Região norte do Brasil é comum que o período chuvoso seja caracterizado por precipitações de forte intensidade, enquanto que no período menos chuvoso são frequentes as estiagens de duração variável, elevando o risco das atividades agrícolas.

Contudo, a realidade da maioria dos municípios tocantinenses é marcada pela ausência de dados sistematizados e regionalizados que auxiliem no planejamento e gestão. As prefeituras municipais raramente possuem banco de dados locais contendo os registros dos volumes precipitados, dos eventos críticos, e da dinâmica do ciclo anual das chuvas da região, mesmo que diversos setores necessitem, ou possam ser beneficiados pela disponibilização dessas informações.

Em outros estados brasileiros diversos aspectos relacionados ao comportamento das precipitações a nível regional, ou municipal, são objeto de estudo: no município de Maxaranguape - RN, Silva (2011) analisou ciclo anual de precipitação como função de índices de instabilidade termodinâmica e fluxos de energia estática; Pessoa (2015) analisou o ciclo diário de precipitações pluviais para o município de Fortaleza - CE; Silva (2015) desenvolveu uma pesquisa sobre os ciclos de precipitação na região de Boa Vista - RR.

O Tocantins é o estado mais jovem da Federação, logo é natural que não possua tantos trabalhos quanto os demais estados brasileiros. Todavia, o estado se localiza próximo a uma região muito estudada no Brasil e em grande parte da América do Sul: a região amazônica. Essa proximidade permite que o clima e as características do estado sejam explorados em trabalhos sobre o clima da Amazônia, além de possibilitar o desenvolvimento de análises mais pontuais.

Marcuzzo e Goularte (2013) realizaram a caracterização do ano hidrológico e mapeamento espacial das chuvas nos períodos úmido e seco do estado do Tocantins. No entanto, o estado possui grande variação espacial das precipitações em seu território, e diversos municípios em desenvolvimento dependem de informações mais pontuais para melhoria dos seus serviços.

Nesse sentido, o município de Araguaína, um dos maiores e mais populosos do estado, está aplicando recursos e desenvolvendo diversos projetos no setor de saneamento, principalmente, na macrodrenagem de algumas sub-bacias municipais. Para esse tipo de projeto são indispensáveis dados locais que caracterizem a dinâmica do ciclo anual de precipitações.

Diante disso, o objetivo desse trabalho é analisar e caracterizar o regime pluviométrico do município de Araguaína, com base nas séries históricas de estações pluviométricas da Agência Nacional de Águas (ANA). Além disso, apresentar informações regionalizadas que podem auxiliar o sistema de gestão do município de Araguaína para os setores que dependem da dinâmica das chuvas em suas tomadas de decisão.

\section{Material e Métodos}

\subsection{A área de estudo}

O município de Araguaína está localizado na região norte do Estado do Tocantins ( $7^{\circ} 11^{\prime} 28^{\prime}$ ' de latitude e $48^{\circ}$ 12'26" de Longitude) e possui área de 4.000,42 $\mathrm{km}^{2}$. Faz parte da Bacia Hidrográfica do Rio Araguaia, que tem como principal afluente o Rio Lontra. Os principais córregos que cortam a cidade são o Lavapés, Prata, Neblina, Raizal, ribeirão de Areia, Xixebal, Cará, Jacubinha, Tiúba e o Jacuba. O córrego Neblina é o que possuí maior relevância para o município, pois compõe o sistema de macrodrenagem que drena a região do núcleo de maior ocupação da cidade e onde se verifica a ocorrência de poços profundos de grandes vazões. A região apresenta clima do tipo tropical úmido, com temperatura máxima oscilando entre 30 e $34^{\circ} \mathrm{C}$ e mínima entre 19 e $21^{\circ} \mathrm{C}$. A vegetação que predomina na região é o cerrado, mas parte do terri- 
tório do município é constituída por floresta de transição entre o cerrado e a floresta amazônica (Araguaína, 2013).

De acordo com o último censo realizado pelo Instituto Brasileiro de Geografia e Estatística (IBGE), Araguaína possui uma população de 150.484 habitantes e é a maior cidade do norte do estado. Além disso, é o município com o $2^{\circ}$ maior PIB do Tocantins, devido principalmente à atividade agropecuária (IBGE, 2018).

\subsection{Dados utilizados}

A ANA disponibiliza de forma livre em sua plataforma virtual as séries históricas de estações pluviométricas espalhadas pelo país, entretanto é muito comum que essas séries históricas possuam falhas em suas medições, uma vez que os registros são realizados manualmente. Ademais, a simples disponibilidade não é a solução, visto que se as informações não forem sistematizadas e regionalizadas são de pouco proveito para os municípios.

Nesta pesquisa foram utilizados dados anuais e mensais de precipitação do banco de dados da ANA de estações próximas a Araguaína, referentes ao período de 1985 a 2014.

De acordo com a Agência, a bacia Araguaia-Tocantins possui 503 estações pluviométricas, porém grande parte destas estações não possuem séries históricas ou possuem séries incompletas.

A região onde se localiza o município possui apenas 3 estações pluviométricas, e apenas uma dessas possui série histórica.

Outros autores utilizaram diferentes bases de dados para estimativa de precipitação em regiões com escassez de estações como, por exemplo, bases dados retiradas da Tropical Rainfall Measuring Mission (TRMM), sendo que as correlações obtidas quando os dados são comparados com as estações pluviométricas são, em sua maioria, muito satisfatórias (Campos, 2017; Nóbrega, Souza e Galvíncio, 2008; Massagli, Victoria e Andrade, 2011; Morais e Ferreira, 2015).

Não obstante, bases de dados como a TRMM são mais complexas, as informações para sua composição são obtidas no site da National Aeronautics and Space Administration (NASA) em formato de rasters e precisam ser trabalhadas em programas de geoprocessamento. Esse tipo de mão de obra e expertise nem sempre está à disposição em todos os municípios, enquanto que a base de dados disponibilizada pela ANA é simples, intuitiva e permite o desenvolvimento de análises rápidas e precisas.

A fim aumentar o número de estações estudadas, foram analisadas algumas estações locadas fora da área do município, sendo desconsideradas aquelas que não possuíam séries históricas, aquelas que possuíam séries inferiores a 30 anos de dados, as que não possuíam dados até 2014, e por fim, as estações localizadas fora de um raio máximo de $500 \mathrm{~km}$ da cidade Araguaína.
Quanto mais próximas as estações, menores as chances de haver discrepâncias significativas entre seus dados, de modo que a análise dos dados precipitação é muito mais fácil e confiável, se estações e os critérios de locação são os mesmos ao longo das redes (WMO, 2008).

A Fig. 1 apresenta a localização das estações pluviométricas da ANA selecionadas para o estudo.

O percentual de contribuição de cada uma das estações para o regime hidrológico de Araguaína e as precipitações médias foram calculadas pelo Método de Thiessen, metodologia definida por polígonos traçados que delimitam a abrangência de cada estação.

Segundo Macêdo et. al (2013) esse método é frequentemente utilizado em áreas de grande extensão e onde não existe uma distribuição uniforme de pluviômetros no interior da bacia. Outros autores em pesquisas sobre a dinâmica da precipitação em outras regiões do Brasil utilizaram esse método de modo satisfatório (Casado, 2012; Mendonça, Sena e Santos, 2015; Velloso, 2015; Souza, Souza e Cardoso, 2017).

A Fig. 2 apresenta o mapa das regiões de abrangência e percentuais de cada umas das estações selecionadas no município de Araguaína, definidos pelos polígonos de Thiessen.

Foram excluídos os pluviômetros cujas áreas de medição não contribuíam diretamente para determinação das precipitações do munícipio de Araguaína, sendo então selecionadas 5 estações pluviométricas. As estações que não apresentaram relevância para a área de Araguaína não foram consideradas no cálculo das precipitações médias.

A estação 748003 abrange maior área dentro do município, totalizando um percentual de quase $36 \%$ do território estudado.

\subsection{Preenchimento de falhas}

A maioria das séries históricas disponibilizadas pela ANA e analisadas neste trabalho apresentaram falhas consideráveis nos anos de 2006 e 2007. Em 83,33\% das estações analisadas no Tocantins nesse trabalho há falhas nos anos de 2006 e 2007, ou em apenas um desses anos.

A Tabela 1 sintetiza as principais características das 5 estações selecionadas.

Nas aplicações dos métodos da regressão linear e da ponderação regional com base em regressões lineares para preenchimento de falhas em estudos relacionados aos regimes pluviométricos é recomendado adotar, como critério mínimo, a obtenção de coeficiente de correlação superior a 0,7 entre as estações, valor comumente adotado por outros autores (Oliveira et al. 2010; Barbosa et al. 2005; Pruski et al. 2004).

No presente estudo não foi possível realizar o preenchimento de nenhuma falha, primeiro por não haver correlação superior a 0,7 em nenhuma das estações, e segundo por conta de as falhas serem praticamente todas nos mesmos anos. 


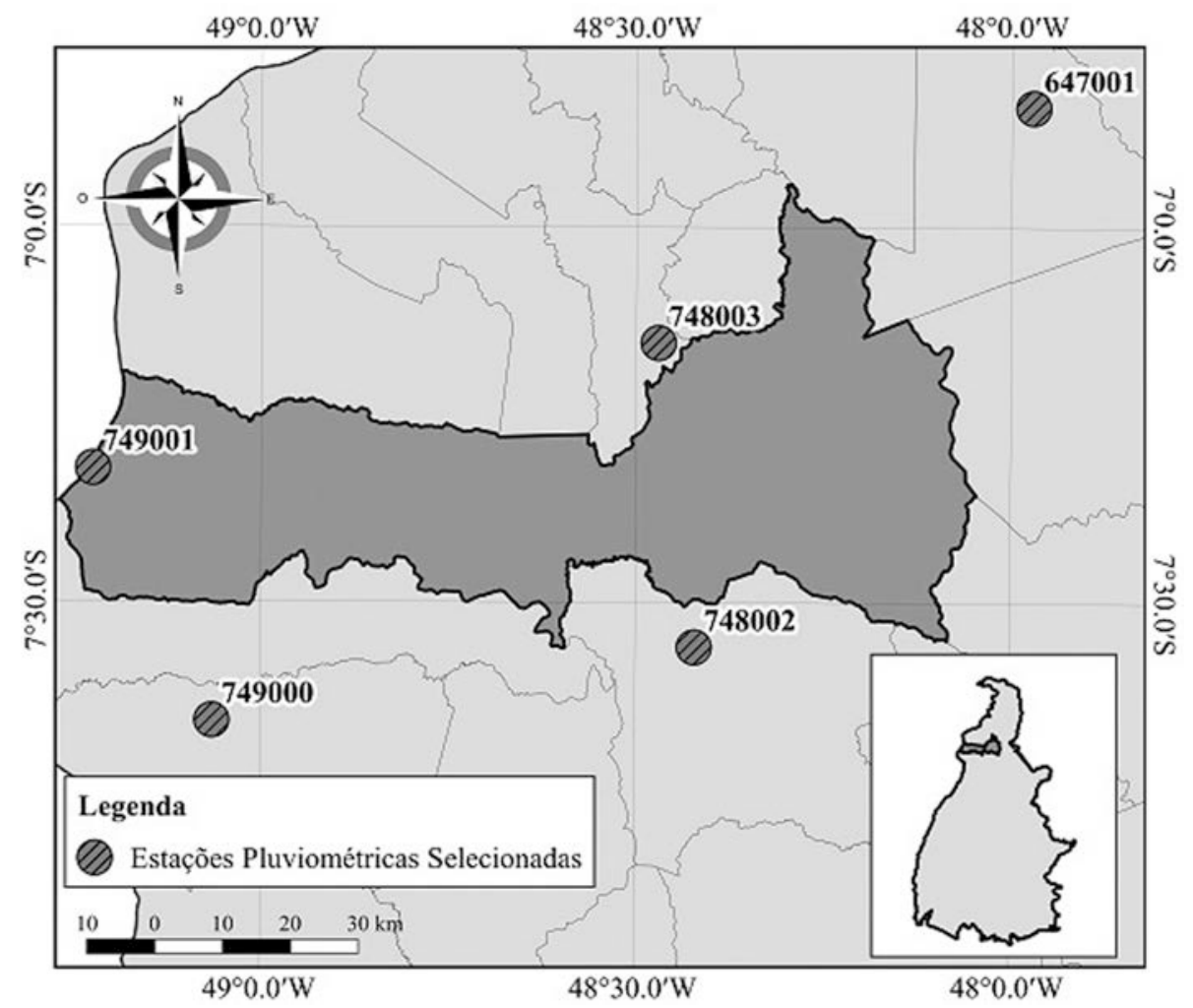

Figura 1 - Mapa da localização das estações pluviométricas selecionadas.

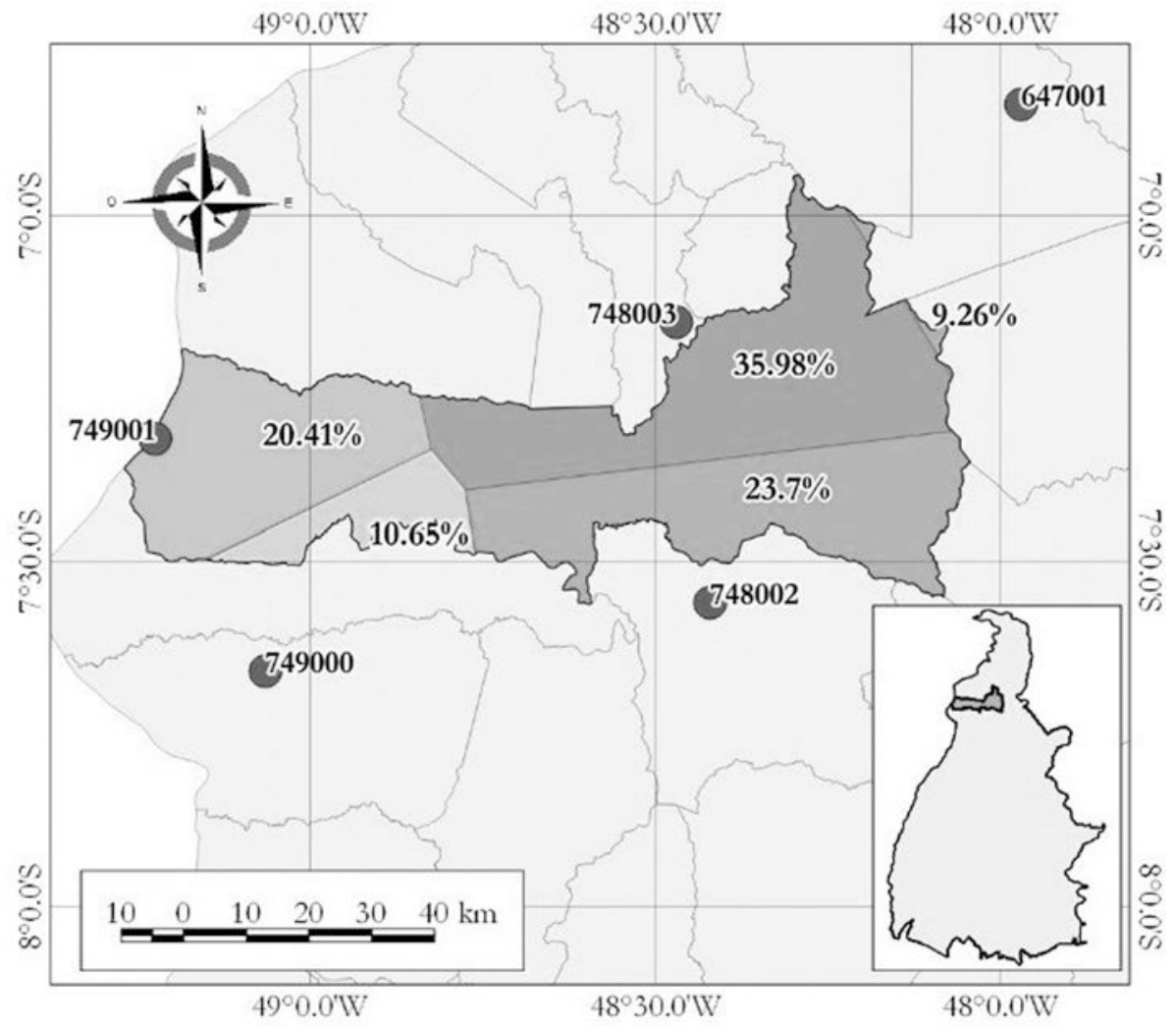

Figura 2 - Mapa das regiões de abrangência e percentuais de cada estação. 
Tabela 1 - Percentual de falhas nas estações selecionadas.

\begin{tabular}{ccccc}
\hline Código & Município & Abrangência & Anos das Falhas & Falhas \\
\hline 748003 & Muricilândia & $35,98 \%$ & 2007,2012 & $6,7 \%$ \\
749001 & Araguaína & $20,41 \%$ & 2006,2007 & $6,7 \%$ \\
647001 & Wanderlândia & $9,26 \%$ & $2006,2007,2014$ & $10,0 \%$ \\
748002 & Nova Olinda & $23,7 \%$ & 2012,2013 & $6,7 \%$ \\
749000 & Arapoema & $10,65 \%$ & - & $0,0 \%$ \\
\hline
\end{tabular}

Contudo, essas falhas não apresentam padrões, não ocorrem de modo sistemático e são pontuais na região e no período, assim não descaracterizam o estudo e, conforme apontam Baddour, Kontongomde e Trewin (2007), apenas adicionam uma quantidade modesta de incerteza na estimativa da análise.

Os procedimentos de controle de qualidade são utilizados para detectar e identificar os erros cometidos durante os processos de obtenção e sistematização de dados, tornando-se essenciais para a qualidade e confiança das análises que envolvem esses dados (WMO, 2002).

No caso, o controle de qualidade aplicado aos valores anuais analisados foi a verificação da homogeneidade dos registros de precipitação, por meio do método da Curva de Dupla Massa, para cada uma das estações selecionadas isoladamente.

Assim, os totais anuais de precipitação da estação de referência e a soma dos totais acumulados de estações vizinhas são plotados em um gráfico, onde os valores das ordenadas correspondem aos da estação de referência e nas abscissas os totais médios anuais das demais estações. Esse método consiste na análise da estação de interesse e de sua relação com as mais próximas, e foi utilizado, com sucesso, em outros estudos (Sanches, Verdum e Fisch, 2013; Silva, 2017; Oliveira, 2010; Souza, Souza e Cardoso, 2017).

\subsection{Os histogramas de precipitação}

$\mathrm{Na}$ caracterização de regimes pluviométricos diversos fatores devem ser considerados, como, por exemplo, a definição do ano hidrológico, a identificação dos valores de lâmina máximos mensais e anuais, e os eventos críticos tanto de máximas quanto de mínimas.

Segundo Marcuzzo e Goularte (2013, p. 91) "a determinação e a caracterização do ano hidrológico, bem como a distribuição espacial e o volume pluviométrico precipitado, são importantes fatores diversos estudos em pluviometria e fluviometria dentro do ciclo hidrológico de uma região".

$\mathrm{O}$ ano hidrológico é a sistematização do ciclo anual de precipitação, de determinada região, dividido em um período contínuo de doze meses. Essa análise permite a distinção do ciclo da chuva em: período chuvoso e período seco (Kich, Melati e Marcuzzo, 2015).
A determinação do ano hidrológico do município de Araguaína se deu pela análise dos totais mensais das médias históricas das estações selecionadas no intervalo de 1985 a 2014.

Por sua vez, a caracterização do regime pluviométrico do município de Araguaína ocorreu por meio da elaboração de histogramas com valores médios mensais, máximos mensais, totais anuais identificando os eventos críticos de data e lâmina, e pela espacialização das precipitações totais anuais para os períodos seco e chuvoso, nas estações selecionadas no estudo.

\section{Resultados e Discussão}

\subsection{As séries históricas}

Um dos motivos que pode justificar a inexistência de dados entre os períodos de 2006 e 2007 é o estado "bruto" dos dados. A ANA realiza uma análise prévia dos dados fornecidos que elimina medições grosseiras e assegura, em parte sua homogeneidade. Esses dados são classificados como consistidos.

Os dados brutos, por sua vez, não passaram por essa análise e, comumente, apresentam disparidades e falhas. Os dados consistidos da ANA, para a Bacia AraguaiaTocantins, geralmente são anteriores a 2006. Contudo, esse fato não esclarece definitivamente o caráter pontual dessas falhas.

A Fig. 3 apresenta a curva de dupla massa para a estação escolhida como de referência, a estação 748003, devido a sua maior abrangência dentro do município.

É importante que para que se confirme a homogeneidade dos dados os valores dos registros anuais de precipitação obedeçam a uma tendência linear. A desproporcionalidade na distribuição dos pontos no gráfico indica possíveis anormalidades na estação: mudança de local, avarias no aparelho, e até alterações no método de observação.

A análise da Curva de Dupla Massa observou o intervalo total de dados do estudo, de 1985 a 2014, para cada uma das estações selecionadas. Essa análise consistiu na identificação de possíveis anomalias gráficas e eventuais desvios dos dados históricos sistematizados.

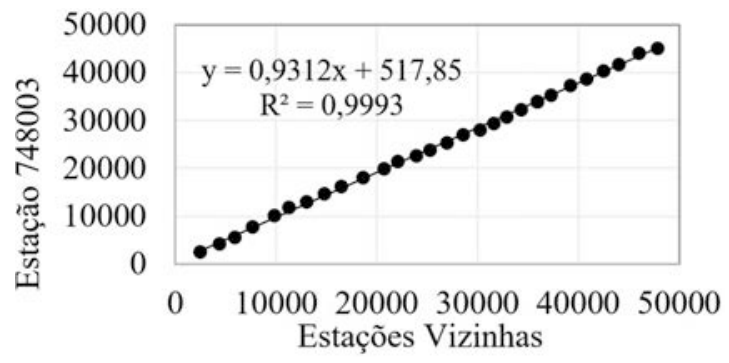

Figura 3 - Curva de dupla massa da estação 748003. 
O gráfico plotado apresenta os valores totais anuais acumulados no sentido do passado para o presente, a equação de tendência linear dos valores anuais e a correlação entre esses valores.

O comportamento linear dos dados e os coeficientes de determinação próximos de 1,0 permitem observar a sua homogeneidade regional, e a consistência nos dados da série histórica.

\subsection{O ano hidrológico}

Por meio da análise dos totais mensais das precipitações médias das estações foi possível desenvolver o histograma que representa o Ano Hidrológico de Araguaína (Fig. 4).

Durante os 30 anos estudados nas estações pluviométricas os meses de fevereiro e março apresentaram maiores médias de precipitação. $\mathrm{O}$ mês de março registra precipitações de 284,8 mm, enquanto que o mês de julho costuma ser o mais seco do ano, com médias de 9,3 $\mathrm{mm}$ precipitados.

Quanto as análises anuais, no ano de 1985 ocorreu um evento crítico, o ano de maior volume de precipitação registrado com total de $3086,8 \mathrm{~mm}$, sendo que a média de precipitação total anual dos 30 anos estudados para toda a área do município é de $1746,97 \mathrm{~mm}$.

No ano de 2007 registrou-se o menor volume anual registrado, 393,9 $\mathrm{mm}$, valor muito abaixo da média anual do período analisado. Uma possível explicação seria a grande quantidade de falhas nas medições desse ano.

A sazonalidade do ano hidrológico do município de Araguaína é bem definida, caracterizada por dois períodos: o período seco de maio a setembro e o chuvoso de outubro a abril.
Esse resultado é muito próximo do encontrado por outros autores que desenvolveram estudos sobre a caracterização hidrológica do Tocantins e da região norte do Brasil.

De acordo com Marcuzzo e Goularte (2013), o ano hidrológico do Tocantins se inicia em outubro, que é o primeiro mês chuvoso após um período seco. A estação das chuvas tem duração de sete meses, vai de outubro a abril, e a estação de estiagem dura cinco meses, se estendendo de maio a setembro.

Souza (2017) em trabalho sobre a caracterização hidrológica do Rio das Fêmeas-BA, região próxima ao Tocantins, aponta que a distribuição mensal da precipitação no período de 1985 a 2013 apresenta clara distinção das estações chuvosa e seca, onde o período chuvoso se inicia no mês de setembro, se estendendo até maio, e o período chuvoso retorna a partir de outubro se estendendo até abril.

\subsection{Distribuição espacial das precipitações}

A região norte brasileira é dividida em três núcleos de precipitação abundantes: o noroeste amazônico é a região com maiores valores de precipitação onde os totais anuais são superiores a $3.000 \mathrm{~mm}$; o segundo núcleo é o central, e é composto justamente pela região central da Amazônia, com médias de precipitação de 2.500 mm/ano; por fim, o terceiro núcleo é o mais próximo do Tocantins, a região sul amazônica, com precipitação acima de $1.750 \mathrm{~mm} /$ ano (Marengo, 2003).

Segundo Aquino (2005) na distribuição espacial das chuvas na região mais ao norte da bacia Araguaia, na região onde se encontra o município de Araguaína, as precipitações aumentam consideravelmente, podendo superar os $2.000 \mathrm{~mm}$ por ano. Marcuzzo e Goularte (2013) apon-

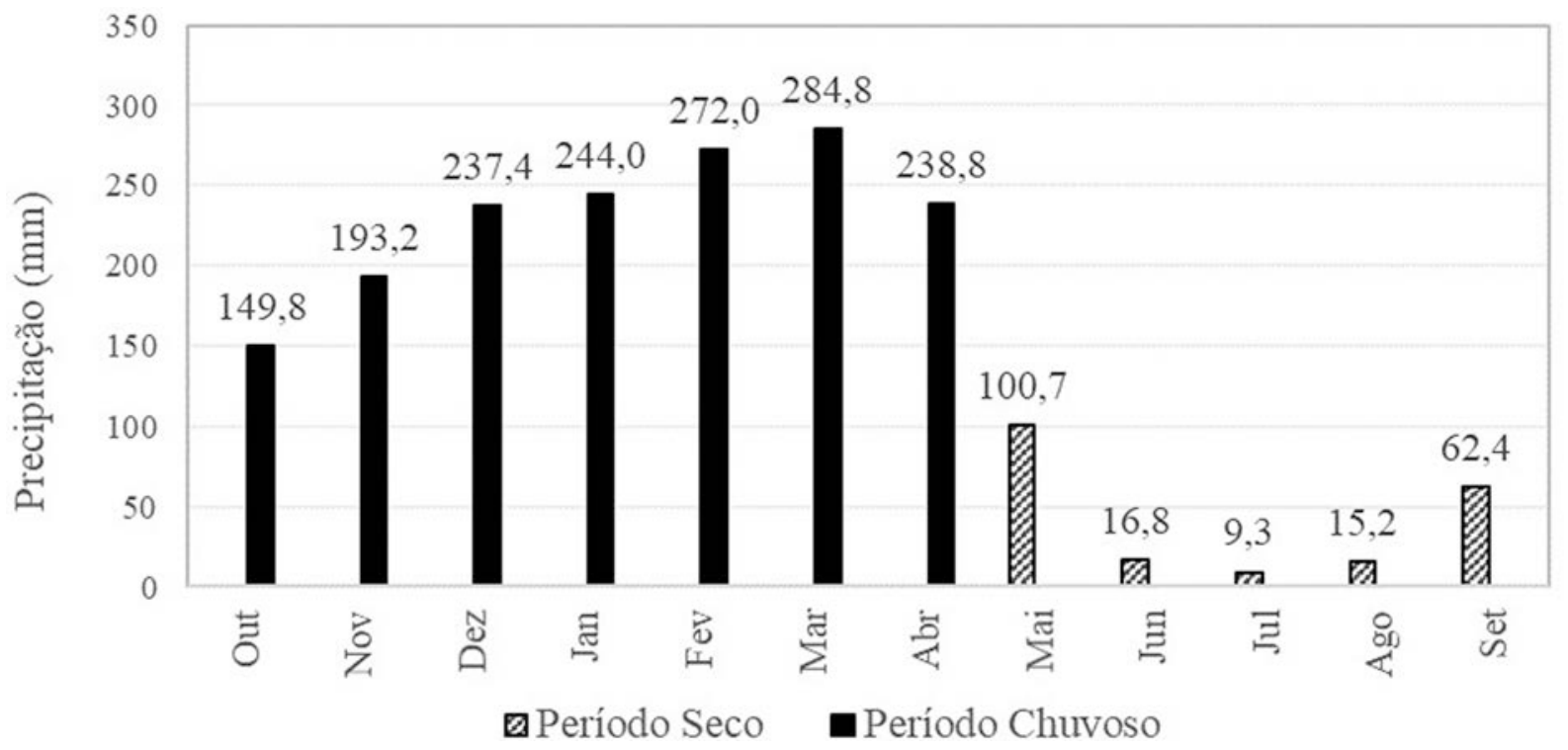

Figura 4 - Ano hidrológico. 
tam que no período de estiagem tocantinense o total pluviométrico registrado em seu estudo foi superior a $200 \mathrm{~mm}$ e no período úmido esse total superou os $1.900 \mathrm{~mm}$.

Em Araguaína, tanto os menores valores de pluviosidade, quanto os maiores ocorreram na porção nordeste, região onde a cidade de Araguaína, sede administrativa do município, fica localizada.

A estação pluviométrica que abrange essa porção é a 748003, do município de Muricilândia, à aproximadamente $27 \mathrm{~km}$ da cidade de Araguaína. Essa estação é locada com altitude de 393 metros, a mais alta das cinco selecionadas, uma das condições de relevo que segundo Silva (2015) e Cavalcanti (2012) é um dos fatores naturais de grande influência para o controle e espacialização dos índices de precipitação. Outrossim, é comum que em áreas mais altas exista menos interferência externa nos registros das estações, fator que contribui consideravelmente para a qualidade dos dados.

Durante o período seco, dos meses de maio a setembro, na maior parte do município a precipitação média registrada foi próxima dos $183 \mathrm{~mm} /$ ano (Fig. 5). A tendência, no período seco, é que à medida que se aumenta a distância da porção nordeste, nas proximidades da cidade de Araguaína, em direção as porções mais periféricas ao sul e sudeste do município, maiores são os volumes médios registrados.
As estações pluviométricas 748002 e 749000, ao sul do município, registram pluviosidade média de 201,38 e 195,91 mm/ano no período seco.

Durante o período chuvoso, dos meses de outubro a abril, a tendência se inverte e se percebe que quanto mais próximo a porção nordeste maiores são os volumes médios registrados. Nas proximidades da cidade de Araguaína os volumes médios de precipitação pluviométrica são superiores aos $1.660 \mathrm{~mm} /$ ano chegando a atingir $1.712,19 \mathrm{~mm} /$ ano na estação 748003 . Nesse período, na maior parte do município, a média precipitada é em torno de $1.645 \mathrm{~mm} /$ ano e os valores mínimos são registrados no extremo leste e extremo oeste e inferiores a $1.559 \mathrm{~mm} / \mathrm{ano}$ (Fig. 6).

Os valores encontrados para o município estão bem próximos dos volumes de precipitação encontrados por Marengo (2003), Aquino (2005) e Marcuzzo e Goularte (2013) para região sul da Amazônia, para a bacia do Tocantins-Araguaia e para o próprio Estado do Tocantins. Em síntese, os valores apresentados pelos autores, para o período chuvoso, variam entre $1.750 \mathrm{e}$ $2.000 \mathrm{~mm} / \mathrm{ano}$.

\section{Conclusão}

Diante da análise das séries históricas de precipitação de cinco estações na ANA, no intervalo de 1985

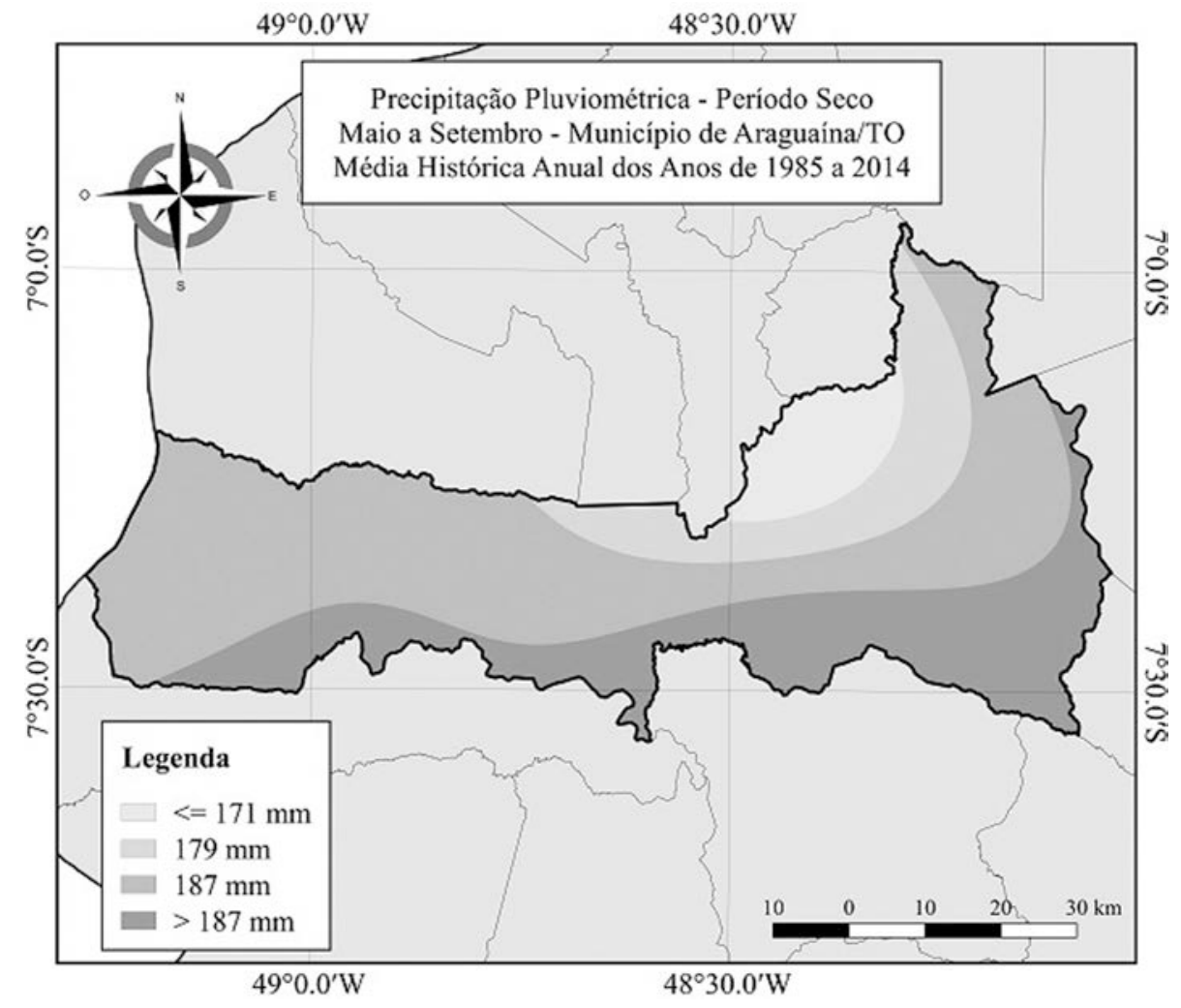

Figura 5 - Distribuição das precipitações média no período seco. 


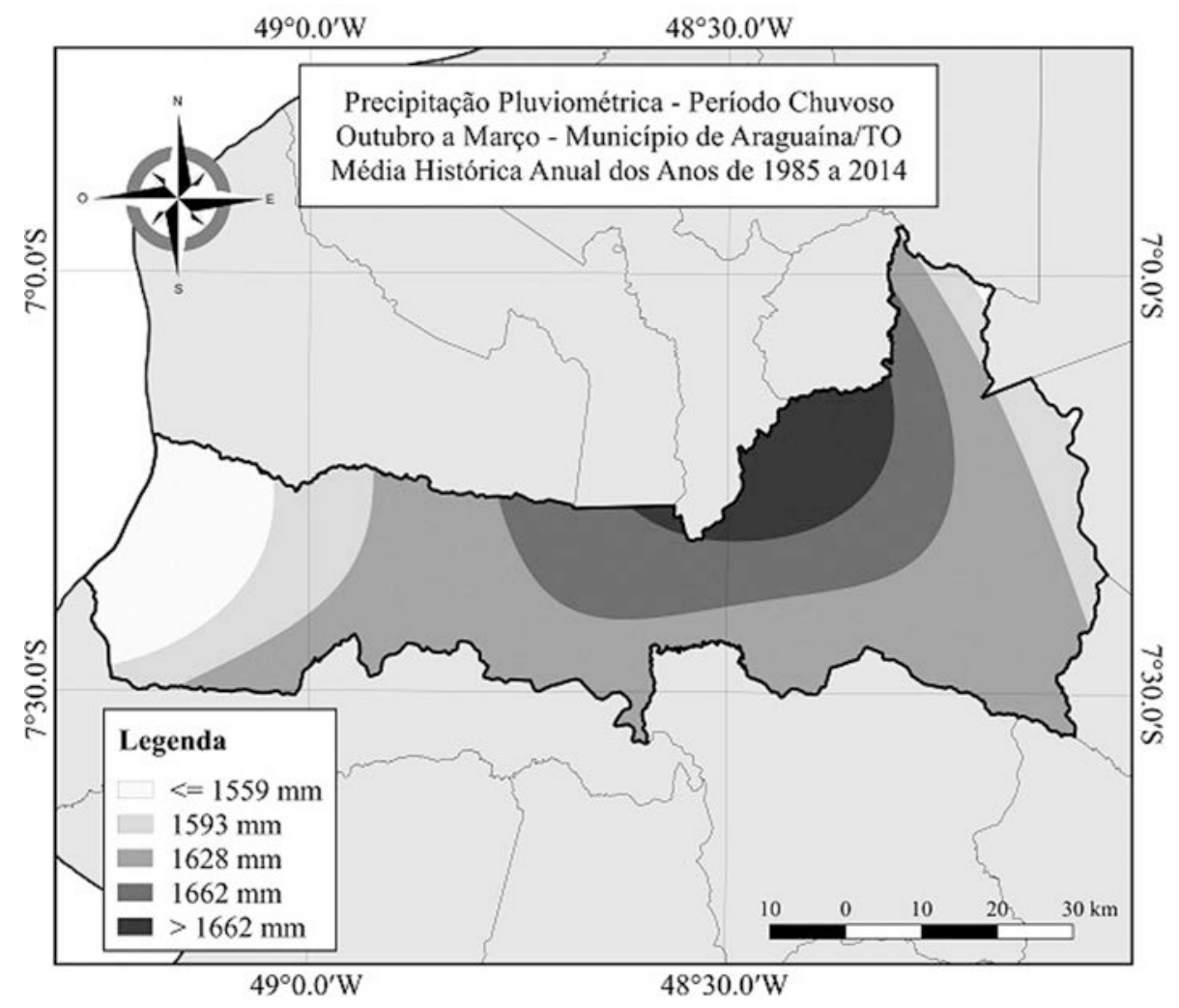

Figura 6 - Distribuição das precipitações média no período chuvoso.

a 2014, foi possível caracterizar o regime pluviométrico do município de Araguaína e observar o comportamento da precipitação nesse período de 30 anos.

O Tocantins é o estado mais novo da Federação e a grande maioria dos seus municípios não possui informações regionalizadas sobre o comportamento das chuvas ao longo do ano, nem tão pouco possui séries históricas de precipitação sistematizadas a disposição para auxiliar nas tomadas de decisão dos gestores municipais.

A importância de pesquisas de caráter local ultrapassa o meio científico e pode colaborar no cotidiano, com o crescimento e desenvolvimento de diversas localidades. Deste modo, é de suma importância que mais trabalhos sejam realizados explorando as características meteorológicas regionais do Tocantins a semelhança do que é feito em outras cidades brasileiras.

Os valores médios de precipitação obtidos nesse trabalho para o município de Araguaína se mantiveram próximos dos valores habituais registrados em outros trabalhos desenvolvidos ao longo da Bacia Tocantins-Araguaia e da região Amazônica.

A metodologia de análise dos dados é recorrente na literatura e as séries histórias podem ser obtidas gratuitamente no portal da ANA de forma simples, intuitiva e sem burocracia, um conjunto de ferramentas e informações que dão possibilidade para impulsionar as pesquisas relacionadas ao tema.
A percepção a respeito da gestão das cidades tem evoluído muito nos últimos anos, e se torna cada vez mais recorrente ideia de desenvolvimento inteligente pautada na otimização dos recursos.

Essa visão holística de desenvolvimento tem exigido cada vez mais a interdisciplinaridade do conhecimento, atualmente informações como a sazonalidade do período chuvoso são ferramentas que podem contribuir diretamente para o planejamento de diversos setores: agronomia, transporte, drenagem, construção civil. As pesquisas que exploram esses campos, principalmente em nível local, colaboram cada vez mais com essa realidade.

O município de Araguaína apresenta um ano hidrológico de sazonalidade bem definida, possuindo dois períodos bem distintos: o período seco de maio a setembro e o chuvoso de outubro a abril. Se bem utilizado, o conhecimento desse comportamento pode servir como alavanca para transformar o planejamento municipal de diversos setores.

Além disso, verificou-se que os maiores volumes pluviométricos precipitados são registrados próximos a sede do município, onde há o maior densidade urbana, e que, segundo a distribuição sazonal das chuvas no município, em média $89 \%$ da precipitação total anual de Araguaína é registrada no período considerado chuvoso, ou seja, pouco mais de $10 \%$ do volume precipitado acontece fora dos meses de outubro a abril. 


\section{Referências}

AQUINO, S.; STEVAUX, J.C.; LATRUBESSE, E.M. Regime hidrológico e aspectos do comportamento morfohidráulico do rio Araguaia. Revista Brasileira de Geomorfogia, v. 6, n. 2, p. 29-41, 2005.

ARAGUAÍNA. Prefeitura Municipal. Secretaria Municipal de Planejamento, Meio Ambiente, Ciência e Tecnologia. Plano Municipal de Água e Esgoto (PMAE). 2013.

ASSIS, W.L. Variações temporais e espaciais da precipitação em áreas urbanas: estudo de caso na região oeste do município de Belo Horizonte. Geosul, v. 24, n. 48, p. 177-196, 2009.

AYOADE, J.O. Introdução à Climatologia para os Trópicos. São Paulo: DIFEL, 1986.

BADDOUR, O.; KONTONGOMDE, H.; TREWIN, B. The Role of Climatological Normals in a Changing Climate. Geneva: World Meteorological Organization, 2007. Disponível em: http://www.wmo.int/pages/prog/wcp/wcdmp/ documents/WCDMPNo61.pdf. Acesso em: 5 set. 2018.

BARBOSA, S.E.S.; BARBOSA JÚNIOR, A.R.; SILVA, G.Q.; CAMPOS, E.N.B. RODRIGUES, V.C. Geração de modelos de regionalização de vazões máximas, médias de longo período e mínimas de sete dias para a bacia do Rio do Carmo, Minas Gerais. Revista de Engenharia Sanitária e Ambiental, v. 10, n. 1, p. 64-71, 2005.

BRASIL. Agência Nacional de Águas. Superintendência de Gestão da Rede Hidrometeorológica. Diretrizes e Análises Recomendadas para a Consistência de Dados Pluviométricos. Brasília: ANA, SGH, 2011.

CAMPOS, R.F. Comparação Entre Dados de Precipitação Interpolados e do TRMM (3B43V7). 2017. 54 p. Dissertação de Mestrado em Produção Vegetal, Universidade Federal do Espírito Santo, Centro de Ciências Agrárias e Engenharias. 2017.

CASADO, G.W.; BARROSO, L.B.; SILVA, F.P.; WOLFF, D.B.; CRUZ, J.C. Polígonos de Thiessen para a bacia hidrográfica do rio da Várzea, no Rio Grande do Sul. In: Congresso Internacional de Tecnologias para o Meio Ambiente, 3, 25-27 abr. 2012, Bento Gonçalves-RS. Anais eletrônicos. Bento Gonçalves: FIEMA, 2012.

CAVALCANTI, I.F.A. Large scale and synoptic features associated with extreme precipitation over South America: A review and case studies for the first decade of the 21 st century. Atmospheric Research, v. 118, p. 27-40, 2012.

IBGE - Instituto Brasileiro de Geografia e Estatística. (2018). Cidades. Disponível em: https://cidades.ibge.gov.br/brasil/ to/araguaina/panorama. Acesso em: 24 abr. 2018.

IPCC - Intergovernmental Panel on Climate Change. 2014. Climate Change 2014: Synthesis Report. Contribution of Working Groups I, II and III to the Fifth Assessment Report of the Intergovernmental Panel on Climate Change. IPCC, Geneva, Switzerland, 151 pp.

KICH, E.M.; MELATI, M.D.; MARCUZZO, F.F.N. Estudo do regime hídrico pluvial e fluvial na sub-bacia 86 visando a determinação do seu ano hidrológico. In: Anais 21 Simpósio Brasileiro de Recursos Hídricos. Brasília: $\mathrm{ABRH}$, 2015.

MACÊDO, M.N.C.; DIAS, H.C.T.; COELHO, F.M.G.; ARAÚJO, E.A.; SOUZA, M.L.H.; SILVA, E. Precipitação pluviométrica e vazão da bacia hidrográfica do Riozinho do
Rôla, Amazônia Ocidental. Revista Ambiente \& Água, Taubaté, v. 8, n. 1, p. 206-221, 2013.

MARCIANO, A.G.; BARBOSA, A.A.; SILVA, A.P.M. Cálculo de precipitação média utilizando método de Thiessen e as linhas de cumeada. Revista Ambiente \& Água, Taubaté, v. 13, n. 1, 2018.

MARCUZZO, F.F.N.; GOULARTE, E.R.P. Caracterização do Ano Hidrológico e Mapeamento Espacial das Chuvas nos Períodos Úmido e Seco do Estado do Tocantins. Revista Brasileira de Geografia Física, v. 6, n. 1, p.91-99, 2013.

MARCUZZO, F.F.N; ROMERO, V. Influência do El Niño e La Niña na precipitação máxima diária do Estado de Goiás. Revista Brasileira de Meteorologia, v. 28, n. 4, p. 429440, 2013.

MARENGO, J.A. Condições climáticas e os recursos hídricos no norte brasileiro. In: TUCCI, C.E.M.; BRAGA, B. (Org.). Clima e Recursos Hídricos no Brasil. Porto Alegre: ABRH, 2003.

MASSAGLI, G.O.; VICTORIA, D.C.; ANDRADE, R.G. Comparação entre precipitação medida em estações pluviométricas e estimada pelo satélite TRMM. In: Anais Eletrônicos 5 Congresso Interinstitucional de Iniciação Científica. Campinas: CIIC, 2011.

MENDONÇA, M.C.S.; SENA, I.M.N.; SANTOS, M.R.A. Comparação dos métodos da média aritmética e de thiessen para determinação da pluviosidade média da sub-bacia do Rio Siriri. In: Anais eletrônicos 2 Congresso Internacional “Gestão da Água e Monitoramento Ambiental: desafios e soluções locais e nacionais". Aracajú: RESAG, 2015.

MORAES, B.C.; COSTA, J.M.N.; COSTA, A.C.L.; COSTA, M.H. Variação espacial e temporal da precipitação no estado do Pará. Acta Amazonica, v. 35, n. 2, p. 207-214, 2005.

MORAIS, L.B.; FERREIRA, N.C. Banco de Dados Pluviométricos Integrados por Dados do Sensor TRMM e Estações Pluviométricas no Estado de Goiás. In: Anais Eletrônicos 17 Simpósio Brasileiro de Sensoriamento Remoto. João Pessoa: INPE, 2015.

NÓBREGA, R.S.; SOUZA, E.P.; GALVÍNCIO, J.D. Análise da estimativa de precipitação do TRMM em uma sub-bacia da Amazônia Ocidental. Revista de Geografia, v. 25, n. 1, p. 6-12, 2008.

OLIVEIRA, L.F.C.; FIOREZE, A.P.; MEDEIROS, A.M.M.; SILVA, M.A.S. Comparação de metodologias de preenchimento de falhas de séries históricas de precipitação pluvial anual. Revista Brasileira de Engenharia Agrícola e Ambiental, v. 14, n. 11, p. 1186-1192, 2010.

OLIVEIRA FILHO, J.C.; PINTO, E.S.; SABOYA, L.M.F.; PERON, A.J.; CAETANO, G.F. Caracterização do regime pluviométrico da região do projeto Rio Formoso na bacia do Araguaia, TO. Acta Amazonica, v. 31, n. 2, p. 221-221, 2001.

PESSOA, F.E.P.; CAMPOS, J.N.B. Ciclo diário de precipitações pluviais em intervalos de cinco minutos no município de Fortaleza. Revista Brasileira de Meteorologia, v. 30, n. 2, p. 195-204, 2015.

PIAZZA, G.A.; TORRES, E.; MOSER, P.; GOTARDO, R.; KAUFMANN, V.; PINHEIRO, A. Análise Espacial e Temporal dos Dados de Precipitação das Estações de Entorno da Bacia do Ribeirão Concórdia, Lontras (SC) Visando Sua 
Inserção no Contexto de Mudanças Climáticas. Revista Brasileira de Meteorologia, v. 31, n. 4 (suppl.), p. 580592, 2016.

PRUSKI, F.F.; PEREIRA, S.B.; NOVAES, L.F.; SILVA, D.D.; RAMOS, M.M. Precipitação média anual e vazão específica média de longa duração, na Bacia do São Francisco. Revista Brasileira de Engenharia Agrícola e Ambiental, v.8, n. 2, p.247-253, 2004.

SANCHES, F.O.; VERDUM, R.; FISCH, G. Estudo de tendência de chuvas de longo prazo. Revista Ambiente \& Água, v. 8, n. 3, p. 214-228, 2013.

SANTOS, I. et al. Hidrometria Aplicada. Curitiba: Instituto de Tecnologia para o Desenvolvimento, 2001.

SILVA, V.B.S.; KOUSKY, V.E.; SHI, W.; HIGGINS, R.W. An Improved Gridded Historical Daily Precipitation Analysis for Brazil. Journal of Hydrometeorology, v. 8, p. 847861, 2007.

SILVA, A.R.; SANTOS, T.S.; QUEIROZ, D.E.; GUSMÃO, M.O.; SILVA, T.G.F. Variações no índice de anomalia de chuva no semiárido. Journal of Environmental Analysis and Progress, v. 2, n. 4, p. 377-384, 2017.

SILVA, C.M.S.; SILVA, F.R.; LEME, N.P. Ciclo anual de precipitação como função de índices de instabilidade termodinâmica e fluxos de energia estática: análises em Maxaranguape-RN. Revista Brasileira de Meteorologia, v. 26, n. 2, p. 235-242, 2011.

SILVA, D.A.; SANDER, C.; ARAÚJO JÚNIOR, A.C.R.; WANKLER, F.L. Análise dos ciclos de precipitação na região de Boa Vista - RR nos anos de 1910 a 2014. Revista Geográfica Acadêmica, v. 9, n. 2, p. 34-49, 2015.

SILVA, R. M.; SILVA, L. P.; MONTENEGRO, S.M.G.L.; SANTOS, C.A.G. Análise da variabilidade espaço-temporal e identificação do padrão da precipitação na Bacia do Rio Tapacurá, Pernambuco. Sociedade \& Natureza, v. 22, n. 2, p. $357-372,2010$.
SOARES, A.S.D.; PAZ, A.R.; PICCILLI, D.G.A. Avaliação das estimativas de chuva do satélite TRMM no Estado da Paraíba. Revista Brasileira de Recursos Hídricos, v. 21, n. 2, p. 288-299, 2016.

SOUZA, E.B. Precipitação sazonal sobre a Amazônia Oriental no período chuvoso: observações e simulações regionais com o REGCM3. Revista Brasileira de Meteorologia, v. 24, n. 2, p. 111-124, 2009.

SOUZA, N.S.; SOUZA, W.J.; CARDOSO, J.M.S. Caracterização hidrológica e influência da cobertura do solo nos parâmetros de vazão do Rio das Fêmeas. Revista de Engenharia Sanitária e Ambiental, v. 22, n. 3, p. 453-462, 2017.

TAO, H.; GEMMER, M.; BAI, Y; MAO, W. Trends of stream flow in the Tarim River Basin during the past 50 years: Human impact or climate change? Journal of Hydrology, v. 400, n. 1-2, p. 1-9, 2011.

VELLOSO, S.G.S.; SANTOS, D.L.; FERREIRA FILHO, J.G.A. Pluviometria da bacia do rio São Miguel, Minas Gerais, Brasil. Enciclopédia Biosfera, v. 11 n. 22, p. 2383-2391, 2015.

WANDERLEY, H.S.; CARVALHO, A.L; FERNANDES, R.C.; SOUZA, J.L. Mudança no Regime Temporal da Temperatura do ar e Precipitação Pluviométrica na região de Rio Largo, Alagoas. Revista Brasileira de Geografia Física, v. 7, n. 4, p. 662-667, 2014.

WMO, 2002. WMO Technical Document 1125, GCOS-76. Geneva: WMO.

WMO, 2008. Guide to Meteorological Instruments and Methods of Observations, WMO-N ${ }^{\circ} 8$, Seventh edition, Geneva: WMO.

License information: This is an open-access article distributed under the terms of the Creative Commons Attribution License (type CC-BY), which permits unrestricted use, distribution and reproduction in any medium, provided the original article is properly cited. 